\title{
Desempenho e características de carcaça de novilhos terminados em pastagem de aveia preta e azevém anual com diferentes níveis de suplementação energética
}

\author{
Performance and carcass characteristics of steers supplemented with corn in an oats \\ and annual ryegrass pasture
}

\author{
Fábio Schuler Medeiros ${ }^{I *}$ Harold Ospina Patino ${ }^{\mathrm{I}}$ Mario Andrés Sierra Cano ${ }^{\mathrm{I}}$ \\ Dimas Correa Rocha ${ }^{\text {II }}$ Félix González ${ }^{\text {II }}$
}

\section{RESUMO}

Foi avaliado o efeito da suplementação energética sobre o desempenho e as características de carcaça de 24 novilhos cruza Aberdeen Angus x Charolês terminados aos 24 meses em pastagem de azevém anual (Lollium multiflorum L.) e aveia (Avena strigosa Schreb) manejada em condições de oferta de forragem não limitante ao desempenho animal. Os tratamentos foram níveis de 0;0,4;0,8 e 1,2\% PV de oferta de concentrado à base de milho moído e minerais. Os animais foram abatidos à medida que atingiram um mínimo de 4,5mm de espessura de gordura na garupa (P8), avaliado por meio de ultrassonografia. Não foram observadas diferenças significativas sobre a deposição de gordura, avaliada in vivo por ultrassonografia ao final da etapa de desempenho, e sobre o ganho médio diário, que apresentaram valores médios de $3,9 \mathrm{~mm}$ e $1,54 \mathrm{~kg} \mathrm{~d}^{-1}$, respectivamente. A avaliação dos parâmetros bioquímicos séricos evidenciou redução linear dos níveis de ureia e aumento linear para os níveis de colesterol, sem que diferenças significativas fossem observadas sobre os níveis de glicose e triglicerídios. A suplementação produziu incremento linear no rendimento de carcaça e no ganho médio diário de carcaça. Entretanto, não foram observadas diferenças significativas sobre a área de olho de lombo, o peso de abate e o peso de carcaça quente, que apresentaram valores médios de $67,85 \mathrm{~cm}^{2}, 438,95 \mathrm{~kg}$ e $227,75 \mathrm{~kg}$. Os níveis crescentes de suplementação utilizados produziram incremento no rendimento e ganho médio diário de carcaça, sem alterações significativas sobre os demais parâmetros de desempenho e carcaça avaliados.

Palavras-chave: pastagem de inverno, parâmetros sanguíneos, suplementação.

\section{ABSTRACT}

The impact of energy supplementation on the performance and carcass caracteristics of 24 Aberdeen Angus

\begin{abstract}
$x$ Charolais steers grazing an annual ryegrass (Lollium multiflorum L.) and Oats (Avena strigosa Schreb) pasture managed in order to avoid constrains to animal performance was evaluated. Treatments were levels of supplementation of 0 ; $0.4 ; 0.8$ and $1.2 \%$ BW with a corn and mineral based supplement. Animals were slaughtered as they achieve $4,5 \mathrm{~mm}$ of fat cover in the rump (P8) evaluated ultrasonography. No differences were observed in fat deposition, measured in live animals with ultrasound at the end of performance period, and in live weight gain, which showed average values of $3,9 \mathrm{~mm}$ and $1,54 \mathrm{~kg} \mathrm{~d} d^{-1}$ respectively. Blood serum levels of urea were linearly decreased and cholesterol linearly increased by energy supplementation, with no differences in the serum levels of glucose and triglicerides. Energy supplementation linearly increased the killing-out proportion and carcass weight gain, but no differences were observed on the rib eye area, slaughter weight and hot carcass weight, wich averaged $67,85 \mathrm{~cm}^{2}$, $438,95 \mathrm{~kg}$ e $227,75 \mathrm{~kg}$. Increasing the levels of supplementation resulted in higher killing-out proportion and higher carcass daily gains, without changes in performance and carcass parameters evaluated.
\end{abstract}

Key words: blood parameters, supplementation, winter pasture.

\section{INTRODUÇÃo}

A exploração da pecuária de corte no Rio Grande do Sul é realizada quase que exclusivamente em pastagens nativas. Porém, a cada ano, em função da busca dos produtores por uma atividade com maior lucratividade, maiores áreas de campo nativo são destinadas à agricultura, forçando a cadeia da carne a buscar a eficiência, a produtividade e a intensificação dos sistemas de produção. Dentro do processo de

\footnotetext{
IPrograma de Pós-graduação em Zootecnia, Departamento de Zootecnia, Universidade Federal do Rio Grande do Sul (UFRGS). Av. Bento Gonçalves, 7712, Agronomia, 91540-000, Porto Alegre, RS, Brasil. E-mail: fsmedeiros@terra.com.br; harold.patino@ufrgs.br. *Autor para correspondência.
}

IIPrograma de Pós-graduação em Ciências Veterinárias, Faculdade de Medicina Veterinária, UFRGS, Porto Alegre, RS, Brasil. 
otimização do uso dos recursos forrageiros, considerado como a alternativa mais viável e ecologicamente correta para a região Sul do Brasil, opções como a integração lavoura-pecuária, com a implantação subsequente de pastagens cultivadas de inverno (Lolium spp., Avena spp., Trifolium spp., Lotus spp., etc.) e a suplementação, podem ser indicadas dentro dos sistemas de produção de carne de qualidade.

Diversos trabalhos têm demonstrado efeitos positivos da utilização de suplementos energéticos sobre o ganho de peso por área (FREITAS et al., 2005; PILAU et al., 2005) e, consequentemente, sobre a rentabilidade do empreendimento, além de incrementos no desempenho em condições de oferta de forragem restrita. Entretanto, em condições em que a disponibilidade de pasto não foi limitante, tem-se observado pouca ou nenhuma influência da suplementação energética sobre o ganho de peso por animal (FRENCH et al., 2001; BERETTA et al., 2006).

Por outro lado, a suplementação energética de animais em pastagens de inverno pode melhorar a eficiência de utilização dos nutrientes absorvidos para a síntese de tecidos ou produtos de origem animal (DIXON \& STOCKDALE, 1999), amenizando o desequilíbrio nutricional (relação proteína/energia), especialmente nas fases extremas de utilização da pastagem, incrementando a taxa de ganho de peso e as características da carcaça de novilhos (ARELOVICH et al., 2003).

Este trabalho teve o objetivo de avaliar o efeito de níveis crescentes de suplementação energética sobre o desempenho e as características de carcaça de novilhos de corte terminados em pastagem de azevém anual (Lollium multiflorum L.) e aveia preta (Avena strigosa Schreb.), com massa de forragem não limitante ao desempenho animal.

\section{MATERIAL E MÉTODOS}

O trabalho foi realizado no período de 01 de julho a 06 de novembro de 2006, em propriedade rural localizada no Município de Restinga Seca, pertencente à região fisiográfica denominada Depressão Central do Estado do Rio Grande do Sul (RS), a 29 49 48” de latitude sul e $53^{\circ} 31^{\prime} 12^{\prime}$ " longitude oeste, com altitude aproximada de $95 \mathrm{~m}$. O clima da região corresponde ao subtropical úmido (MORENO, 1961), e o solo pertence à unidade de mapeamento São Pedro, classificado como Argisolo Vermelho distrófico Arênico (EMBRAPA, 1999).

Foi utilizado um potreiro com área de 11,25ha, onde foi implantada uma pastagem mista de aveia preta (Avena strigosa Schreb) e azevém anual (Lolium multiflorum L.), ambos semeados a lanço com $64 \mathrm{~kg}$ de aveia e 38kg de azevém por ha em consorciação, em 03 de maio de 2006. A adubação foi de $230 \mathrm{~kg}$ da fórmula 05.30.15 no plantio e, posteriormente, duas aplicações de $60 \mathrm{~kg}$ de ureia em cobertura, nos dias 06 de agosto e 14 de setembro de 2006.

A disponibilidade de forragem na pastagem foi determinada por metodologia indireta utilizando o aparelho Sward Stick (HODGSON, 1990). A altura da pastagem foi medida em pelo menos 200 pontos na área experimental a cada 28 dias, e o valor médio das medições foi utilizado como variável independente em equações de regressão linear que relacionaram os valores de medição de altura às medições de massa de forragem real, realizadas na mesma data, em 15 pontos da área experimental, utilizando-se um quadrado de $0,25 \mathrm{~m}^{2}$.

A taxa de acúmulo de forragem foi determinada utilizando-se seis gaiolas de exclusão de 0,80m de altura por 1,0m de diâmetro, utilizando o método de gaiolas emparelhadas. A pastagem foi manejada buscando a manutenção de uma massa de forragem entre 1.000 e $1.500 \mathrm{~kg} \mathrm{MS} \mathrm{ha}^{-1}$ e uma altura mínima de $20 \mathrm{~cm}$, visando maximizar o desempenho animal e evitar a competição destes durante o processo de pastejo (POPPI, 1987; CASSOL, 2003; AGUINAGAet al., 2006). Foi assumido um acúmulo inicial de $40 \mathrm{~kg} \mathrm{MS} \mathrm{dia-1}$, e posteriormente foram utilizados os resultados de taxa de acúmulo do período anterior para fins de ajuste de carga e cálculo da oferta real de matéria seca (MS). Os dados médios de disponibilidade, oferta de forragem, altura, taxa de acumulação diária e percentual de material verde são apresentados na tabela 1 .

A composição bromatológica da pastagem foi determinada em amostras de pasto coletadas no $14^{\circ}$ dia de cada período experimental por meio de simulação de pastejo - hand puckling. Foram também coletadas, de forma aleatória, 20 amostras por meio de corte rente ao solo para quantificação do percentual de material verde e morto/senescente na pastagem. Todas as amostras foram secas em estufa com ventilação a $60^{\circ} \mathrm{C}$, por 72 horas, sendo moídas para realização das análises laboratoriais. Foram determinados os teores de fibra em detergente neutro (FDN), fibra em detergente ácido (FDA) e lignina (LDA) (VAN SOEST \& ROBERTSON, 1975), proteína bruta (PB) (AOAC, 1995) e digestibilidade in vitro verdadeira da matéria seca (DIVVMS) e da digestibilidade in vitro verdadeira da matéria orgânica (DIVVMO)(VAN SOEST et al., 1966). A degradabilidade da proteína bruta da pastagem foi calculada utilizando-se a técnica dos sacos de náilon, conforme SAMPAIO et al. (1995). Os resultados da 
Desempenho e características de carcaça de novilhos terminados em pastagem de aveia preta e azevém anual...

Tabela 1 - Valores médios de disponibilidade (DF), oferta de forragem (OMF), altura, taxa de acumulação diária (TAD), \% de material verde; composição bromatológica de matéria orgânica (MO), proteína bruta (PB), fibra em detergente neutro (FDN), fibra em detergente ácido (FDA), lignina detergente ácido (LDA) e digestibilidade in vitro verdadeira da matéria seca (DIVVMS), dados em percentagem, proteína degradável no rúmen (PDR) e relações PB/MO e PDR/MOD das amostras obtidas pela simulação de pastejo na área experimental.

\begin{tabular}{|c|c|c|c|c|c|c|}
\hline \multirow{2}{*}{ Variáveis } & \multicolumn{3}{|c|}{-----------Período avaliação desempenho----------- } & \multicolumn{2}{|c|}{---------Período complementar--------- } & \multirow{2}{*}{ Média } \\
\hline & $01 / 07-29 / 07$ & $30 / 07-26 / 08$ & $27 / 08-23 / 09$ & $24 / 09-21 / 10$ & $22 / 10-06 / 11$ & \\
\hline DF (kg MS ha-1) & 891,72 & 1358,5 & 1654,8 & 1794,6 & 1935,6 & 1527,0 \\
\hline OMF (\%PV dia $\left.{ }^{-1}\right)$ & 12,21 & 16,45 & 12,17 & 20,84 & 12,08 & 14,75 \\
\hline Altura $(\mathrm{cm})$ & 24,1 & 22,97 & 20,64 & 31,20 & 42,28 & 28,24 \\
\hline TAD (kg MS dia $\left.{ }^{-1}\right)$ & 44,98 & 70,11 & 50,64 & 79,22 & N.A & 61,24 \\
\hline Material Verde (\%) & 82,53 & 69,18 & 65,59 & 69,77 & 16,53 & 60,72 \\
\hline$\%$ & \multicolumn{6}{|c|}{ 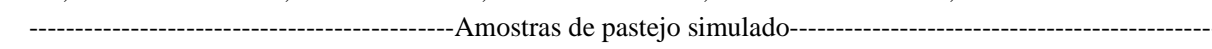 } \\
\hline MO (\% MS) & 89,09 & 89,84 & 91,02 & 92,89 & 93,98 & 91,36 \\
\hline PB (\% MS) & 25,77 & 25,40 & 17,05 & 14.59 & 8,82 & 18,32 \\
\hline PB/MO & 28,93 & 28,27 & 18,73 & 15,71 & 9,38 & 20,05 \\
\hline PDR (\% PB) & 74,9 & 77,7 & 67,7 & 61,3 & 52,8 & 66,88 \\
\hline PDR/MOD & 23,78 & 29,21 & 16,84 & 13,31 & 8,99 & 18,42 \\
\hline FDN (\% MS) & 46,41 & 48,10 & 56,90 & 59,84 & 70,42 & 56,34 \\
\hline FDA (\% MS) & 28,62 & 29,46 & 31,88 & 31,54 & 36,86 & 31,67 \\
\hline LDA(\% MS) & 5,15 & 5,23 & 6,70 & 6,03 & 6,94 & 6,01 \\
\hline DIVVMS (\%) & 72,3 & 60,7 & 62,4 & 62,4 & 48,7 & 61,3 \\
\hline
\end{tabular}

NA - Não avaliado.

análise bromatológica da pastagem nos distintos períodos experimentais são apresentados na tabela 1 .

Os tratamentos consistiram de níveis crescentes de suplemento, definidos como percentagem do peso vivo dos animais (\% PV), da seguinte forma: S-0 - não suplementado; S-0,4 - 0,4\% PV de suplemento; S-0,8 - 0,8\% PV de suplemento; S-1,2-1,2\% PV de suplemento. A formulação dos concentrados e a sua composição química são apresentadas na tabela 2. Todos os animais tiveram acesso permanente à suplementação mineral com sal mineralizado comercial.

Foram utilizados 24 novilhos cruzados (3/4 Aberdeen Angus, 1/4 Charolês), sendo seis animais por tratamento, com peso médio de $281 \mathrm{~kg}$ ( $\pm 16 \mathrm{~kg}$ ), idade entre 16 e 20 meses e condição corporal aproximada de 2,5 (escala de 1-5). Todos os animais pertenciam ao mesmo grupo contemporâneo e foram manejados em campo nativo apenas com suplementação mineral durante os 60 dias anteriores ao início do experimento. No primeiro dia do trabalho, os animais foram pesados após jejum de 12 horas e dosificados com $6 \mathrm{ml}$ de endectocida à base de Ivermectina.

Os animais foram mantidos na mesma área de pastagem e suplementados, diariamente, entre $14 \mathrm{e}$ 16 horas, em canzis individuais, conforme o seu peso médio estimado em cada período experimental. Após seu retorno à pastagem, as sobras de suplemento eventualmente existentes foram individualmente quantificadas. A cada 28 dias, foram realizadas pesagens dos animais precedidas de jejum de 12 horas para ajuste do nível de suplementação e avaliação do desempenho animal, sendo esta última realizada apenas durante os três primeiros períodos experimentais antes que se iniciassem os abates dos animais. Nessa etapa, também foram coletadas amostras de sangue para análises bioquímicas de ureia, glicose, triglicerídios e colesterol, sendo utilizados kits analíticos comercias. A conversão do suplemento (CS) foi calculada dividindo-se o ganho de peso individual do animal em cada período pelo respectivo consumo de suplemento.

Os animais foram abatidos no Frigorífico Silva Ltda., em Santa Maria, RS, nos dias 26 de setembro, 12 outubro e 06 novembro de 2006, à medida que atingiam o valor mínimo de 4,5mm de espessura de gordura subcutânea, avaliado por meio de medidas na garupa do animal (ponto P8) com um aparelho de ultrassonografia do modelo Falcon 100 (Piemedics), com sonda de $6 \mathrm{MHz}$, buscando-se a obtenção de animais com graus de acabamento semelhantes.

O peso de carcaça quente foi determinado ao final da linha de abate. O rendimento de carcaça foi calculado com base no peso vivo obtido após jejum de 12 horas, no dia anterior ao abate, previamente ao carregamento para o frigorífico. O ganho médio diário 
Tabela 2 - Formulação dos suplementos utilizados, composição percentual de proteína bruta (PB) e níveis estimados de nutrientes digestíveis totais (NDT), consumo de suplemento (CONSUPL), conversão do suplemento (CS), peso de abate, número de dias até o abate, ganho de peso médio diário (GMD), ganho de peso médio diário de carcaça (GMDC), espessura de gordura subcutânea no ponto P8 ao final da etapa de desempenho (EGP8US), peso de carcaça quente (PCQ), rendimento de carcaça quente (RCQ), área de olho de lombo (AOL), espessura de gordura subcutânea (EGS), espessura de gordura subcutânea no ponto P8 (EGP8) e parâmetros bioquímicos séricos de ureia, glicose, triglicerídios e colesterol de novilhos submetidos a diferentes níveis de suplementação em pastagem de inverno.

\begin{tabular}{|c|c|c|c|c|c|c|c|}
\hline & \multicolumn{4}{|c|}{-------------------Níveis de Suplementação------------------ } & \multirow{2}{*}{ Médias } & \multirow{2}{*}{ EPE } & \multirow{2}{*}{ Regressãc } \\
\hline & $\mathrm{S}-0$ & S- 0,4 & $\mathrm{~S}-0,8$ & $\mathrm{~S}-1,2$ & & & \\
\hline \multicolumn{8}{|l|}{ Ingredientes (\%) } \\
\hline Grão de milho moído & - & 94,93 & 96,91 & 97,60 & & & \\
\hline Calcário calcítico & - & 0,94 & 1,01 & 1,01 & & & \\
\hline Sal & - & 0,83 & 0,42 & 0,29 & & & \\
\hline Premix & - & 3,12 & 1,59 & 1,07 & & & \\
\hline Enxofre ventilado & - & 0,18 & 0,07 & 0,03 & & & \\
\hline Monensina sódica & - & 0,023 & 0,012 & 0,008 & & & \\
\hline \multicolumn{8}{|l|}{$\underline{\text { Composição }}$} \\
\hline $\mathrm{PB}$ & - & 8,03 & 8,47 & 8,31 & & & \\
\hline NDT (estimado) & - & 84,82 & 86,83 & 87,54 & & & \\
\hline \multicolumn{8}{|l|}{$\underline{\text { Variáveis }}$} \\
\hline CONSUPL (\% PV) & 0 & 0,38 & 0,67 & 0,96 & & & NA \\
\hline CS (kg PV kg-1 supl) & - & 1,29 & 0,64 & 0,48 & & & $\mathrm{~L}$ \\
\hline Peso Abate (kg) & 440,83 & 448,33 & 421,50 & 445,16 & 438,95 & 6,63 & NS \\
\hline $\mathrm{N}^{\circ}$ dias até abate & 110 & 112,5 & 92 & 98,8 & & & NA \\
\hline GMD (kg dia $\left.{ }^{-1}\right)$ & 1,486 & 1,501 & 1,533 & 1,661 & 1,545 & 0,038 & NS \\
\hline GMDC $\left(\mathrm{kg} \mathrm{dia}^{-1}\right)$ & 0,778 & 0,816 & 0,885 & 0,950 & 0,85 & 0,02 & $\mathrm{~L}$ \\
\hline EGP8US (mm) & 3,61 & 3,52 & 4,26 & 4,40 & 3,95 & 0,2 & NS \\
\hline PCQ (kg) & 224,23 & 231,65 & 221,40 & 233,75 & 227,75 & 3,79 & NS \\
\hline RCQ (\%) & 50,85 & 51,66 & 52,50 & 52,55 & 51,89 & 0,35 & $\mathrm{~L}$ \\
\hline $\mathrm{AOL}\left(\mathrm{cm}^{2}\right)$ & 67,75 & 67,08 & 65,55 & 70,66 & 67,85 & 1,35 & NS \\
\hline EGS -Abate (mm) & 2,24 & 2,91 & 2,9 & 3,3 & 2,8 & 0,18 & NS \\
\hline EGP8 - Abate (mm) & 4,4 & 5,2 & 5,3 & 6,0 & 5,2 & 0,29 & NS \\
\hline Ureia (mg dl $\left.{ }^{-1}\right)$ & 37,02 & 33,40 & 34,90 & 29,49 & 33,70 & 0,88 & $\mathrm{~L}$ \\
\hline Glicose (mg dl ${ }^{-1}$ ) & 82,07 & 81,99 & 85,64 & 84,48 & 83,54 & 1,41 & NS \\
\hline Colesterol (mg dl ${ }^{-1}$ ) & 113,62 & 119,85 & 124,39 & 139,37 & 124,30 & 3,50 & $\mathrm{~L}$ \\
\hline Triglicerídios $\left(\mathrm{mg} \mathrm{dl}^{-1}\right)$ & 39,67 & 38,12 & 37,83 & 35,88 & 37,87 & 0,85 & NS \\
\hline
\end{tabular}

* Não houve interação entre tratamentos e diferentes datas de coleta $(\mathrm{P}>0,05)$ para os parâmetros bioquímicos séricos.

** L = Linear; NS = Não Significativo; NA = Não avaliado por regressão linear.

*** EPE - erro padrão da estimativa.

de carcaça (GMDC) foi calculado considerando-se um rendimento de $51 \%$ dos animais ao início do experimento, o número de dias até o abate e o peso de carcaça quente de cada novilho. Após o resfriamento, as carcaças foram cortadas na altura da $13^{a}$ costela, sendo avaliadas nessa posição a área de olho de lombo (AOL) e a espessura de gordura subcutânea (EGS) (MULLER, 1987).

O experimento foi conduzido em um delineamento completamente casualizado. Os resultados foram submetidos à análise de regressão linear, utilizando-se o consumo de concentrado como variável independente, sendo testadas as regressões linear, quadrática e cúbica para cada variável experimental, conforme o modelo $\mathrm{Y}_{\mathrm{ij}}=\mu+\beta_{1} \mathrm{~T}_{\mathrm{i}}+$ $\beta_{2} T_{i}^{2}+\beta_{3} T_{i}^{3}+\varepsilon_{i j}$ em que $\mu$ é o efeito médio, Yij é a ijésima observaçã̀o associada ao i-ésimo tratamento, (1 é o regressor associado ao efeito linear do i-ésimo tratamento, (2 é o regressor associado ao efeito quadrático do i-ésimo tratamento, $\beta_{3}$ é o regressor associado ao efeito cúbico do i-ésimo tratamento e $\varepsilon_{\text {.i. é }}$ o ij-ésimo erro associado à ij-ésima observação. Ôs resultados do GMD, da conversão suplemento (CS) e dos parâmetros bioquímicos séricos, entre períodos, foram avaliados como medidas repetidas nas mesmas unidades experimentais, em parcelas subdivididas, 
conforme o modelo $\mathrm{Y}_{\mathrm{ijk}}=\mu+\mathrm{T}_{\mathrm{i}}+\mathrm{A}_{\mathrm{j}}+(\mathrm{AT})_{\mathrm{ij}}+\mathrm{P}_{\mathrm{k}}+(\mathrm{PT})_{\mathrm{ik}}$ $+\varepsilon_{\mathrm{ijk}}$, em que $\mu$ é o efeito médio, $\mathrm{Y}_{\mathrm{ijk}}{ }_{\mathrm{ij}}$ é a j-ésima observação associada ao i-ésimo tratamento no k-ésimo período, T é o efeito associado ao i-ésimo tratamento, $A_{j}$ é o efeito associado ao j-ésimo animal; (AT) $)_{i j}$ é o efeito associado ao j-ésimo animal dentro do i-ésimo tratamento (Erro A), $\mathrm{P}_{k}$ é o efeito do k-ésimo período de observação, $(\mathrm{PT})_{\text {ik }}$ é a interação entre o i-ésimo tratamento e o k-ésimo período de observação e $\varepsilon_{\mathrm{ijk}}$ é erro associado à j-ésima observação do i-ésimo tratamento dentro do k-ésimo período (Erro B). As análises foram realizadas utilizando o PROC GLM do SAS (1999). As variáveis espessura de gordura subcutânea e espessura de gordura P8 não apresentaram distribuição normal no teste de WilkShapiro e visualizado no diagrama de ramos e folhas, sendo então comparadas pelo teste não paramétrico de Kruscall-Wallis, PROC NPAR1WAY do SAS (1999).

\section{RESULTADOS E DISCUSSÃO}

O consumo observado dos suplementos foi inferior ao planejado em função da elevada disponibilidade média de forragem $\left(1.527 \mathrm{~kg} \mathrm{ha}^{-1}\right)$, oferta $(14,75 \% \mathrm{PV})$ e qualidade nutricional da pastagem (PB 18,32\%; DIVVMS -61,3\%, FDN -56,34\%), sendo observados consumos médios de suplemento de 0,38 ; 0,67 e 0,96\% PV para os tratamentos S-0,4; S-0,8 e S-1,2 respectivamente.

O nível de suplementação não afetou a taxa de ganho de peso dos animais (GMD) $(\mathrm{P}>0,05)$, que apresentou um valor médio de $1,545 \mathrm{~kg} \mathrm{dia}^{-1}$ durante a fase de avaliação do desempenho. A conversão do suplemento (CS) diminuiu de forma significativa com o incremento dos níveis de suplementação, apresentando valores médios de 1,$29 ; 0,64$ e $0,48 \mathrm{~kg} \mathrm{PV} \mathrm{kg}^{-1}$ suplemento, respectivamente, para os níveis de 0,4 ; 0,8 e 1,2\% PV de suplementação, não sendo observada interação significativa entre tratamentos e períodos. De forma conjunta, os efeitos sobre o GMD e a CS podem ser explicados pelo efeito de substituição no consumo da forragem pelo suplemento, sem alterações no consumo de energia pelo animal (VAN SOEST, 1994). A utilização de suplementos energéticos em pastagens abundantes de alta qualidade pode gerar taxas de substituição próximas a 1,0 (SCARM, 1990).

FRENCH et al. (2001) observaram decréscimo na resposta do GMD à suplementação com o aumento da oferta de forragem ao suplementar novilhos com níveis crescentes de concentrado.

Os GMD observados no presente experimento foram superiores aos observados por AGUINAGA et al. (2006), os quais observaram ganhos médios diários de $1,14 \mathrm{~kg} \mathrm{dia}^{-1}$, e aos observados por CASSOL (2003) (1,0 a 1,20kg dia-1) em pastagens semelhantes, manejadas a mesma altura da utilizada no presente experimento. Os maiores GMD observados no presente experimento podem ser explicados em função da expressão do ganho compensatório, uma vez que os animais sofreram uma restrição alimentar moderada no período que antecedeu o início do experimento. ROSA (2006) observou incremento significativo de $17 \%$ no desempenho de animais consumindo níveis crescentes de concentrado em confinamento, observando ganhos médios de $1,503 \mathrm{~kg}$ dia $^{-1}$ para animais com restrição alimentar e 1,289kg dia ${ }^{-1}$ para animais sem restrição alimentar, com idade e genética semelhantes.

A análise dos dados de desempenho entre os períodos de utilização da pastagem não detectou efeito do nível de suplementação sobre o $\operatorname{GMD}(\mathrm{P}=0,39)$ nem sobre a interação entre tratamentos e períodos $(\mathrm{P}=0,89)$, embora se observou maior desempenho médio no período intermediário $\left(0,98,2,09\right.$ e 1,58 kg animal ${ }^{-1}$ $\mathrm{dia}^{-1}$ ). Os maiores valores de desempenhos observados, durante o período intermediário de utilização da pastagem, podem ser explicados pela plena adaptação dos animais à dieta e a condições experimentais.

Os resultados observados quanto à relação PB/MO (relação proteína bruta/matéria orgânica) e PDR/MOD (relação proteína degradável no rúmen/ matéria orgânica digestível (Tabela 1) mostram que a pastagem apresentava, principalmente nos períodos iniciais, desequilíbrios nutricionais. Pastagens hibernais, no início de seu ciclo vegetativo, apresentam baixa disponibilidade de carboidratos solúveis e elevados teores de proteína degradável no rúmen (HORN et al., 2005), os quais podem ocasionar perdas de nitrogênio e gasto energético com a excreção do nitrogênio que excede a capacidade de síntese de proteína por parte dos microrganismos ruminais (SCARM, 1990). Outros autores têm observado comportamento quadrático do desempenho animal entre períodos sucessivos de utilização de pastagens hibernais de alta qualidade (PILAU et al., 2004).

O ganho de peso dos animais é o resultado da disponibilidade líquida de energia para crescimento e produção e da quantidade de proteína e aminoácidos que chegam ao intestino, até que seja alcançado o limite genético para síntese de proteína e gordura. Segundo POPPI \& MCLENNAN (1995), provavelmente esse limite nunca seja atingido por animais em pastejo. Os autores observaram, analisando informações de animais em pastagens de clima temperado, que, com níveis de proteína bruta superiores a $160 \mathrm{gPB} \mathrm{kg}^{-1} \mathrm{MO}$, haveria perdas de nitrogênio consumido da pastagem, as quais 
seriam convertidas em amônia com gasto energético para o animal.

A abordagem atual sobre o balanceamento de suplementos para maximização da eficiência de utilização dos volumosos e dos nutrientes contidos nas pastagens preconiza a manutenção de relações adequadas entre a proteína degradável no rúmen (PDR) e a matéria orgânica digestível (MOD). SCARM (1990) propõe a utilização de uma relação variável de 170 a 130 g de PDR para cada kg de MO consumida, sendo o primeiro valor para o primeiro corte/pastejo de gramíneas e leguminosas de clima temperado e o seguinte para as demais forragens.

Os animais recebendo o maior nível de suplementação apresentaram uma diminuição de 28,5\% nos níveis séricos de ureia em relação aos animais recebendo os menores níveis de suplementação. Esses dados foram ajustados pela equação linear $\mathrm{Y}=37,11$ $6,77 \mathrm{x}\left(\mathrm{P}=0,01 ; \mathrm{R}^{2}=0,25\right.$; epe $\left.=0,88\right)$. A suplementação energética melhorou a relação $\mathrm{PB} / \mathrm{MO}$ e eficiência de utilização da proteína contida na pastagem consumida pelos animais. Esse melhor equilíbrio nutricional, embora sem efeito significativo no GMD, pode ter favorecido a eficiência de síntese de proteína microbiana e aumentado a eficiência da síntese de novo de ácidos graxos pela maior disponibilidade de equivalentes redutores oriundos da glicólise, assim como pode ter reduzido o dispêndio energético para a detoxificação e excreção do excesso de nitrogênio (na forma de ureia) da dieta, aumentando a disponibilidade de energia para produção.

Os níveis séricos de colesterol diferiram significativamente entre os tratamentos, sendo o efeito linear positivo para os diferentes níveis de suplementação sobre esse parâmetro que são representados pela equação $\mathrm{Y}=111,23+26,24 \mathrm{x}(\mathrm{P}=0,01$; $\mathrm{R}^{2}=0,25$; epe=3,43). A síntese do colesterol é realizada em grande parte no fígado, sendo estimulada pela insulina (LEHNINGER, 1995). Dessa forma, pode-se inferir que a maior disponibilidade de precursores de glicose, com níveis mais elevados de suplementação, produziu incremento na secreção de insulina, estimulando a formação de colesterol.

O nível de suplementação gerou apenas incrementos numéricos nos níveis séricos de glicose ( $\mathrm{P}>0,05)$, apresentando valores médios de $83,54 \mathrm{mg} \mathrm{dl}^{-1}$, pois as amostras de sangue para análise foram coletadas após um período de jejum de 12 horas.

Os níveis séricos de glicose, triglicerídios e colesterol foram superiores aos parâmetros de referência publicados por KANEKO et al. (1997). Isso pode ser explicado em função da elevada taxa de ganho de peso diário observado, da qualidade da dieta e das modificações hormonais e metabólicas produzidas pelo ganho compensatório (DIMARCO et al., 2006).

FRENCH et al. (2001) observaram resultados semelhantes quanto à glicose para níveis crescentes de fornecimento de concentrado, mas não encontraram efeito da suplementação sobre os níveis sanguíneos de ureia. Os valores médios foram $75,3 \mathrm{mg} \mathrm{dl}^{-1}$ de glicose e $32,63 \mathrm{mg} \mathrm{dl}^{-1}$ de ureia, valores inferiores aos observados neste experimento. MARINASSEN et al. (2004) suplementaram bezerros em pastagens de aveia com dois níveis de suplementação, com grãos de aveia. Observaram incremento significativo nos níveis séricos de glicose para o menor nível de suplementação (0,25\% $\mathrm{PV})$, não observando diferenças entre o maior nível de suplementação (0,5\% PV) e o tratamento controle não suplementado, verificando valores de 85, 91 e $81 \mathrm{mg} \mathrm{dl}^{-1}$, respectivamente.

O protocolo experimental foi definido para que todos os animais fossem abatidos a um mesmo grau de acabamento. O nível de suplementação energética não afetou significativamente a deposição de gordura dos animais, avaliada por meio da ultrassonografia (EGP8 Ultrassom), embora tenha sido detectada uma tendência de incremento linear para essa característica $(\mathrm{P}=0,15)$.

Os pesos de abate não diferiram entre os tratamentos $(\mathrm{P}>0,05)$, provavelmente como consequência de os animais terem apresentado taxas de ganho de peso similar, e os abates terem ocorrido a um mesmo grau de acabamento.

O nível de suplementação aumentou linearmente o rendimento de carcaça (RCQ) $(\mathrm{Y}=50,97+$ 1,83x; $P=0,06 ; R^{2}=0,14 ;$ epe $=0,33$ ). Os rendimentos de carcaça observados foram inferiores aos animais confinados por ROSA (2006) e semelhantes aos animais em pastejo de AGUINAGA et al. (2006). Segundo DIMARCO et al. (2006), o RCQ é influenciado pela dieta, pelo peso de abate e pelo grau de acabamento. $\mathrm{O}$ incremento no RCQ observado pode ser atribuído a um menor tamanho do trato digestivo em função da menor quantidade de fibra na dieta para os níveis crescentes de suplementação, uma vez que não houve diferença entre os pesos de abate e o grau de acabamento (CHURCH, 1988).

O ganho médio diário de carcaça (GMDC) respondeu linearmente ao nível de suplementação $\left(Y=0,76+0,18 x ; R^{2}=0,23, P=0,0145\right.$; epe=0,02), evidenciando alteração na composição do ganho de peso com a inclusão do alimento amiláceo na dieta. A utilização de alimentos amiláceos em substituição à pastagem de alta qualidade pode alterar as proporções molares de ácidos propiônico e acético no rúmen, favorecendo a deposição de gordura e proteína, em 
função de um melhor equilíbrio de nutrientes no metabolismo animal e estímulo à secreção de insulina. Segundo DIMARCO et al. (2006), a dieta determina o padrão de nutrientes absorvidos pelo animal, o que pode modificar os padrões hormonais, mediadores do crescimento, receptores hormonais e aspectos metabólicos, sobre os quais pouco se conhece em termos quantitativos. FRENCH et al. (2001) observaram incremento significativo dos rendimentos e do ganho de peso de carcaça com níveis crescentes de suplementação.

A AOL, da mesma forma, não apresentou diferença significativa entre os níveis de suplementação. Utilizada em conjunto com outros parâmetros, a área de olho de lombo auxilia na avaliação do rendimento em cortes desossados da carcaça (MULLER, 1987), estando em alguns trabalhos altamente correlacionada ao total de músculos na carcaça (COSTA, 2001). Os valores médios observados de $67,85 \mathrm{~cm}^{2}$ são similares aos observados por VAZ \& RESTLE (2001) para animais cruzados com Charolês, abatidos em pesos semelhantes aos observados neste experimento.

O nível de suplementação não afetou a EGS $(\mathrm{P}=0,27)$ e EGP8 $(\mathrm{P}=0,35)$, com valores médios de 0,28 e $0,52 \mathrm{~cm}$, respectivamente. Esses valores são próximos aos exigidos pelos frigoríficos estabelecidos no Rio Grande do Sul, que exigem carcaças com EGS mínima aproximada de 3,0mm, avaliada visualmente nas carcaças.

\section{CONCLUSÕES}

Os níveis crescentes de suplemento energético para bovinos terminados em pastagem de aveia preta (Avena strigosa Schreb) e azevém anual (Lolium multiflorum L) não apresentaram efeitos significativos sobre o ganho de peso vivo dos novilhos. Entretanto, aumentaram linearmente os níveis séricos de colesterol, o rendimento e o ganho médio diário de carcaça.

\section{APRESENTAÇÃO}

Este trabalho é parte da Tese de Doutorado do primeiro autor, Fábio Schuler Medeiros

\section{REFERÊNCIAS}

A.O.A.C. Official methods of analysis. 16.ed. Washington, D.C., 1995. 2000p.

AGUINAGA, A.A.Q. et al. Produção de novilhos superprecoces em pastagem de aveia e azevém submetida a diferentes alturas de manejo. Revista Brasileira de Zootecnia, v.35, p.1765-
1773, 2006. Disponível em: <http://www.scielo.br/pdf/rbz/ v35n4s0/a26v354s.pdf>. Acesso em 14/07/09. doi: 10.1590/ S1516-35982006000600026

ARELOVICH, H.M. et al. Performance of beef cattle grazing oats supplemented with energy, escape protein or high quality hay. Animal Feed Science and Technology, v.105, p.2942, 2003.

BERETTA, V. et al. Performance of growing cattle grazing moderate quality legume-grass temperate pastures when offered varyng forage allowance with or without grain supplementation. Australian Jounal of Experimental Agriculture, v.46, p.793-797, 2006.

CASSOL, L.C. Relações solo-planta-animal num sistema de integração lavoura-pecuária em semeadura direta com calcáreo na superfície. 2003. 143f. Tese (Doutorado em Agronomia - Ciência do Solo) - Universidade Federal do Rio Grande do Sul. Disponível em: <http://hdl.handle.net/10183/ 4243>. Acesso em 14/07/09.

CHURCH, D.C. (Ed). El rumiante: fisiologia digestiva e nutrición. Zaragoza: Acribia, 1988. 641p.

COSTA, E.C. Desempenho em confinamento e características da carcaça e da carne de novilhos Red Angus superprecoces abatidos com diferentes pesos. 2001. 99f. Dissertação (Mestrado em Zootecnia - Produção Animal) - Universidade Federal de Santa Maria, RS.

DIMARCO, O.N.et al. Crescimento de bovinos de corte. Porto Alegre:UFRGS, 2006. 248p.

DIXON, R.M.; STOCKDALE, R. Associative effects between forages and grains: consequences for feed utilization. Australian Journal of Agricultural Research, v.50, n.5, p.757-773, 1999.

EMBRAPA. Centro Nacional de Pesquisas de Solos. Sistema brasileiro de classificação de solos. Brasília: EMBRAPA. 1999. 412p.

FREITAS, F.K. et al. Suplementação energética na recria de fêmeas de corte em pastagem cultivada de inverno. Produção animal. Revista Brasileira de Zootecnia, v.34, p.12561266, 2005. Disponível em: Suplementação energética na recria de fêmeas de corte em pastagem cultivada de inverno. Disponível em: <http://www.revistasbz.org.br/scripts/revista/sbz1/Artigos/ 4491.PDF>. Acesso em 14/07/09. doi: 10.1590/S151635982005000400022.

FRENCH, P. et al. Intake and growth of steers offered different allowances of autumn grass and concentrates. Animal Science, v.72, p.129-138, 2001.

HODGSON, J. Grazing management: Science into practice. New York: Longman Scientific and Technial, 1990. 203p.

HORN, G. W. et al. Designing supplements for stocker cattle grazing wheat pasture. Journal of Animal Science., v.83, suppl, p.E69-78, 2005. Disponível em: <http://jas.fass.org/ cgi/content/full/83/13_suppl/E69>. Acesso em 14/07/09.

KANEKO, J.J. et al. Clinical biochemistry of domestic animals. 5.ed. Boston: Academic, 1997. 932p. 
LEHNINGER, A.L. Princípios de bioquímica. 2.ed. São Paulo: Sadvier, 1995. 839p.

MARINASSEN, J. et al. Suplementación con grano de avena de terneros a pastoreo sobre verdeo de avena. 1. composición de la dieta, ganacia de peso y parámetros sanguíneos. Revista Argentina de Producción Animal, 24 (sup.1), 2004. Disponível em: <http://www.aapa.org.ar>. Acesso em 12/01/ 2008.

MOREnO, J.A. Clima do Rio Grande do Sul. Porto Alegre: Secretaria da Agricultura, 1961. 41p.

PILAU, A. et al. Produção de forragem e produção animal em pastagem com duas disponibilidades de forragem associadas ou não à suplementação energética. Revista Brasileira de Zootecnia, v.34, p.1130-1137, 2005. Disponível em: <http:/ /www.scielo.br/scielo.php?script=sci_arttext\&pid=S151635982005000400006\&lng=en\&nrm=iso>. Acesso em 14/07/ 09. doi: 10.1590/S1516-35982005000400006.

PILAU, A. et al. Recria de novilhas de corte com diferentes níveis de suplementação energética em pastagem de Aveia Preta e Azevém. Revista Brasileira de Zootecnia, v.33, p.2104-2113, 2004. Disponível em: <http://www.scielo.br/scielo.php?script=sci_arttext\&pid=S151635982004000800023\&lng=en\&nrm=iso>. Acesso em 14/07/09.

POPPI, D.P.; MCLENNAN, S.R. Protein and energy utilization by ruminants at pasture. Journal of Animal Science, v.73, p.278-290, 1995. Disponível em: <http://jas.fass.org>. Acesso em 14/07/09.

POPPI, D.P. et al. Intake of pasture by grazing ruminants. In: NICOL, A.M. (Ed). Livestock feeding on pasture. Hamilton: New Zealand Society of Animal Production, 1987. 145p.
ROSA, J.P. Exigências energéticas e protéicas de novilhos Aberdeen Angus submetidos ou não ao ganho compensatório. 2006. 149f. Tese (Doutorado em Zootecnia - Produção Animal) - Universidade Federal do Rio Grande do Sul. Disponível em http://hdl.handle.net/10183/11282. Acesso em 14/07/09.

SAMPAIO, I.B.M et al. Optimal design for studing dry matter degradation in the rúmen. Arquivos Brasileiros de Medicina Veterinária e Zootecnia, v.47, p.373-383, 1995.

SAS INSTITUTE. SAS/STAT user guide: statistics. Version 8.2. Cary, 1999. 1CD.

SCARM. Standing Comittee on Agricultural and Resource Management. Ruminants Subcomittee Feeding Standards for Australian Livestock. Ruminants. Melbourn: CSIRO, 1990. 266p.

VAN SOEST, P.J. Nutritional ecology of the ruminant. New York: Cornell University, 1994. 476p.

VAN SOEST, P.J. et al. Estimation of the true digestibility of forages by the in vitro digestion of cell walls. In: INTERNATIONAL GRASSLAND CONGRESS, HELSINKI, 10., 1966, Helsinki Proceedings of... Helsinki: Finish Grassland Association, 1966. p.438-441.

VAN SOEST, P.J.; ROBERTSON, J.B. Analysis of forages and fibrous foods: a laboratory manual for animal science. Ithaca: Cornell University, 1975. 202p.

VAZ, F.N.; RESTLE, J. Efeito de raça e heterose para características de carcaça de novilhos da primeira geração de cruzamento entre Charolês e Nelore. Revista Brasileira de Zootecnia, v.30, p.409-416, 2001. 